the type of barley. This has to be verified. However, the variability obtained by GuildaUme (1978) seems to deny it (4392 $\mathrm{Kcal} / \mathrm{kg}$ dry matter \pm 104).

In addition to the traditional chemical analyses it should therefore be interesting to make a calorimetric measurement with the aim of determining the gross energy.

Use of a mean digestible energy value would have led to rather close results in particular in the second trial. This results from the rather low crude fibre content of the barley lots studied, except the six-row barley of the first trial. The energy correction according to the crude fibre content of the barleys would therefore be very justified with high content lots and applies particularly to the six-row barley as shown by the results of a survey carried out in 1976 1977 (LELONG et al.).

\title{
Feed restriction of fattening pigs: results of five coordinated trials
}

\author{
J. CHAUVEI, ( $\left.{ }^{1}\right)$, D. LE; MEUR ( $\left.{ }^{2}\right)$, J. M. PEREZ $\left({ }^{(}\right)$, \\ J.-P. RIMBERT $\left(^{(4)}\right.$, J.-Y. TIRILLIY ()
}

(1) I.T.P., I49, rue de Bercy, 75595 Paris Cedex I2

(2) E.D.E. du Finistère, Stang Vihan B.P. 504, 29109 Quimper Cedex (France)

(3) I.N.R.A., Station de Recherches sur l'Élevage des Porcs, $7835^{\circ}$ Jouy-en-Josas (France)

(') E.D.E. du Morbihan, Maison de l'Élevage, B.P. 77, I2 bis, bd Richemond, 56000 Vannes (France)

(5) I.T.C.F., 8, avenue du Président-Wilson, 75116 Paris

This experiment was realized in co-operation with several institutes (E.D.E., I.N.R.A., I.T.C.F., I.T.P.) with the aim of determining the effects of ad libitum feeding and of various feed restriction levels under different pig management conditions. Three treatments were compared for each sex: ad libitum feeding and two feed restriction levels.

The feed restriction profiles were progressive and reached a maximum at 2.2 and $2.5 \mathrm{~kg}$ feed per day for the castrated males, 2.5 and $2.8 \mathrm{~kg}$ for the females at $55,7 \mathrm{o}$ and $85 \mathrm{~kg}$ live weight, respectively. A total of 420 animals was used: 240 Large White, I80 crossbred Large White $\times$ Landrace. In two trials out of five, the animals came from "minimal-disease " herds. The average live weight of the animals at the beginning of the experiment was $30 \mathrm{~kg}$ and they were slaughtered at about I03 kg. One only diet (maize-soybean) containing $2.6 \mathrm{~g}$ lysine per Mcal digestible energy was used in all trials. The raw materials used in the diet were the same whatever the location of the experiment.

The castrated males (between 30 to $103 \mathrm{~kg}$ ) fed ad libitum consumed on an average $2.65 \mathrm{~kg}$ feed per day with a maximum of $3.20 \mathrm{~kg}$ ( $\mathrm{T} 0.7 \mathrm{Mcal} \mathrm{D}$. E.) at the end of the fattening period (from $80 \mathrm{~kg}$ to slaughter). The feed restriction schedules applied corresponded on an average to 20 and $25 \mathrm{p}$. Ioo restriction intensities relative to the ad libitum feeding and produced a decrease in weight gain strictly proportional to the restriction intensity $(837 \mathrm{~g} /$ day versus 687 and $643 \mathrm{~g})$ so that the feed efficiency was not modified. Feed restriction of castrated males led on an average to a one month lengthening of the fattening period and allowed to gain one commercial grade as compared to ad libitum feeding. In these conditions, restricted feeding of castrated males is only advantageous in terms of economy if the price difference between grades remains superior to $0.30 \mathrm{FF}$ per $\mathrm{kg}$ carcass.

The female pigs fed ad libitum consumed on an average $2.52 \mathrm{~kg}$ feed per day with a maximum of $3.0 \mathrm{rg}$ at the end of the fattening period (IO.I Mcal D.E.). Roughly, the feed restriction schedules were equivalent to a 14 and $\mathrm{i} 6 \mathrm{p}$. 100 mean restriction and led to a concomitant change in the growth rate $(834 \mathrm{~g} /$ day versus 719 and $709 \mathrm{~g})$. The feed conversion ratio did not change with the feeding level. With restricted feeding, the fattening length of females increased by about two weeks and the commercial grading was slightly improved. In terms of economy, the margins per grade and per year obtained with the two feeding techniques (ad libitum or restricted) were rather close in females whatever the price differences between grades. 